\title{
$\mathrm{NADP}^{+}$-dependent $\mathrm{D}$-xylose dehydrogenase from pig liver
}

\section{Purification and properties*}

\author{
Sergio ZEPEDA, $\dagger$ Octavio MONASTERIO and Tito URETA $\ddagger$ \\ Departamento de Biología, Facultad de Ciencias, Universidad de Chile, Casilla 653, Santiago, Chile
}

\begin{abstract}
An $\mathrm{NADP}^{+}$-dependent $\mathrm{D}$-xylose dehydrogenase from pig liver cytosol was purified about 2000 -fold to apparent homogeneity with a yield of $15 \%$ and specific activity of 6 units $/ \mathrm{mg}$ of protein. An $M_{\mathrm{r}}$ value of 62000 was obtained by gel filtration. PAGE in the presence of SDS gave an $M_{\mathrm{r}}$ value of 32000 , suggesting that the native enzyme is a dimer of similar or identical subunits. D-Xylose, D-ribose, L-arabinose, 2-deoxyD-glucose, D-glucose and D-mannose were substrates in the presence of NADP ${ }^{+}$but the specificity constant (ratio $k_{\text {cat. }} / K_{\text {m(app.) }}$ ) is, by far, much higher for D-xylose than for the other sugars. The enzyme is specific for $\mathrm{NADP}^{+}$; $\mathrm{NAD}^{+}$is not reduced in the presence of $\mathrm{D}$-xylose or other sugars. Initial-velocity studies for the forward direction with xylose or $\mathrm{NADP}^{+}$concentrations varied at fixed concentrations of the nucleotide or the sugar respectively revealed a pattern of parallel lines in double-reciprocal plots. $K_{\mathrm{m}}$ values for D-xylose and $\mathrm{NADP}^{+}$were $8.8 \mathrm{~mm}$ and $0.09 \mathrm{~mm}$ respectively. Dead-end inhibition studies to confirm a ping-pong mechanism showed that $\mathrm{NAD}^{+}$acted as an uncompetitive inhibitor versus $\mathrm{NADP}^{+}\left(K_{\mathrm{i}} 5.8 \mathrm{mM}\right)$ and as a competitive inhibitor versus xylose. D-Lyxose was a competitive inhibitor versus xylose and uncompetitive versus $\mathrm{NADP}^{+}$. These results fit better to a sequential compulsory ordered mechanism with $\mathrm{NADP}^{+}$as the first substrate, but a ping-pong mechanism with xylose as the first substrate has not been ruled out. The presence of D-xylose dehydrogenase suggests that in mammalian liver D-xylose is utilized by a pathway other than the pentose phosphate pathway.
\end{abstract}

\section{INTRODUCTION}

The degradation of pentoses in mammalian liver is generally thought to occur exclusively via the pentose phosphate pathway, i.e. through the phosphorylation of free pentose and later conversion into ribulose 5phosphate (Segal \& Foley, 1959). Alternative pathways involving non-phosphorylated sugars are considered to be non-existent, or dismissed as 'vestiges of primitive pathways' (Horecker, 1968). However, non-phosphorylating alternative pathways for pentose utilization may occur, as attested by the finding in mammalian liver (Metzger \& Wick, 1967; Schachter et al., 1969; Mobley et al., 1970; Ureta \& Radojković, 1970; Yuen \& Schachter, 1972; Maijub et al., 1973) of several NAD ${ }^{+}$ or $\mathrm{NADP}^{+}$-dependent dehydrogenases acting on free pentoses and catalysing the general reaction:

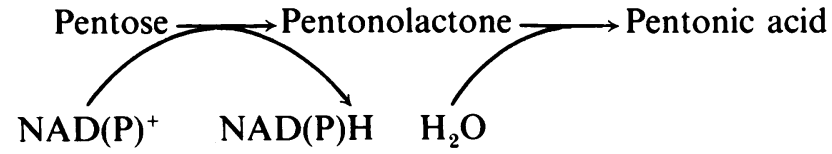

D-Xylose, a pentose present in most organisms, is the main component of hemicellulose, a structural material of all plants, and of heteropolysaccharides of plants, fungi, algae and animal tissues. As part of glycosylaminoglycans bound to proteins, xylose participates as an important structural component of membranes and connective tissue, especially in mammals (Wissler \& Logemann, 1984).

The oxidation of xylose to xylonic acid is known to occur in micro-organisms, and the enzyme involved, D-xylose dehydrogenase [D-xylose: NAD $(P)^{+}$1-oxidoreductase, EC 1.1.1.175] has been identified in several prokaryotes (Buchert et al., 1986), but, as far as we know, it has been studied in some detail in a few species only, as in the case of the enzyme from Arthrobacter sp. (Yamanaka et al., 1977).

It has been shown in mammals that parenteral administration of $\left[1-{ }^{14} \mathrm{C}\right]$ xylose results in ${ }^{14} \mathrm{CO}_{2}$ production. Further, the rate of ${ }^{14} \mathrm{CO}_{2}$ evolution is higher if $\left[1-{ }^{14} \mathrm{C}\right] x y l o n i c$ acid is injected instead. Tissue slices are able to oxidize $\mathbf{D}$-xylose through the intermediate production of D-xylonic acid (Weser \& Laster, 1968).

$\mathrm{NADP}^{+}$-dependent $\mathrm{D}$-xylose dehydrogenases have been isolated from the crystalline lens of calf and pig (van Heyningen, 1958; Wissler, 1977; Wissler \& Logemann, 1984) and from pig liver (Ureta \& Radojković, 1970), but none of those enzymes has been adequately purified and characterized. In view of the possible functional relevance of these dehydrogenases to the catabolism of free xylose, we have focused our attention on an NADP ${ }^{+}$-linked dehydrogenase acting on D-xylose and other related pentoses, previously identified in pig liver by Schiwara et al. (1968) and by Ureta \& Radojković (1970). The enzyme has now been purified to homogeneity and some of its physical and kinetic features

* This work is respectfully dedicated to Professor Dr. Hermann Niemeyer (Departamento de Biología, Facultad de Ciencias, Universidad de Chile) on his 71 st birthday.

$\dagger$ Permanent address: Facultad de Ciencias, Universidad de La Serena, La Serena, Chile.

¥ To whom correspondence and requests for reprints should be addressed. 
were studied. Portions of this work were previously reported and published in abstract form (Zepeda \& Ureta, 1986).

\section{EXPERIMENTAL}

\section{Materials}

Nicotinamide nucleotides, sugars and sugar derivatives, reagents for electrophoresis, phenylmethanesulphonyl fluoride, Reactive Blue 2-agarose and protein markers of known molecular size were products of Sigma Chemical Co. DEAE-cellulose (DE-52) was from Whatman. Hydroxyapatite (Bio-Gel HTP) was from Bio-Rad Laboratories. Other reagents were of the highest purity commercially available. Fresh pig liver was obtained in a local abattoir.

\section{Measurement of xylose dehydrogenase activity}

Xylose dehydrogenase activity was assayed at $30^{\circ} \mathrm{C}$ by measuring the rate of reduction of $\mathrm{NADP}^{+}$at $340 \mathrm{~nm}$ in a medium containing in a final volume of $0.5 \mathrm{ml}$ the following (final concentrations): $10 \mathrm{mM}-\mathrm{KCl}, 85 \mathrm{mM}-$ Tris/HCl buffer, $\mathrm{pH} 7.5,12.6 \mathrm{~mm}-\mathrm{MgCl}_{2}, 1.6 \mathrm{~mm}$-EDTA, 0.5 mM-NADP ${ }^{+}, 100 \mathrm{~mm}$-D-xylose and enzyme (Ureta \& Radojković, 1970). A system without sugar was used as a blank. Modifications of the standard assay system are described in the legends to Figures. One unit of enzyme activity is that amount catalysing the reduction of $1 \mu \mathrm{mol}$ of $\mathrm{NADP}^{+}$in 1 min under the described conditions. Specific activity is defined as units/mg of protein.

A Zeiss PMQ II spectrophotometer, thermostatically maintained at $30^{\circ} \mathrm{C}$ and equipped with an automatic device for sequential monitoring of six simultaneous reactions, was used for the kinetic studies. Initial velocities were determined from the beginning of the progress curves. Substrate depletion was limited to less than $20 \%$. Reactions were initiated by the addition of enzyme. For each experimental point triplicate determinations were performed.

\section{Statistical analysis of the kinetic data}

The initial-velocity and inhibition studies were analysed by using the program NATO, adapted to an IBM personal computer (Cornish-Bowden, 1985), which assesses the required weighting from the data set itself, avoiding the need for the experimenter to make prior assumptions about weights (Cornish-Bowden \& Endrenyi, 1986). The non-linear least-squares regression procedure of the NATO program yields the kinetic parameters, the associated standard errors and goodnessof-fit characteristics.

\section{Purification of D-xylose dehydrogenase}

All operations were performed at $4{ }^{\circ} \mathrm{C}$. Enzyme from each step of the purification procedure was suspended in buffer $\mathrm{A}(5 \mathrm{mM}$-Tris/ $\mathrm{HCl}$ buffer, $\mathrm{pH} 8.5$, containing $1 \mathrm{~mm}$-EDTA, $10 \mathrm{~mm}$-monothioglycerol and $1 \mathrm{~mm}-$ phenylmethanesulphonyl fluoride). Enzyme preparations in buffer A maintained constant activity during 6 months (longer times were not studied). Dialysis and concentration were performed in an Amicon ultrafiltration apparatus.

Preparation of crude extracts. About $300 \mathrm{~g}$ of pig liver was homogenized in a Waring blender with 1 vol. of buffer A. The homogenate was centrifuged at $105000 \mathrm{~g}$ for $60 \mathrm{~min}$ in a Beckman L5-50B ultracentrifuge. The supernatant liquid was used as starting material.

Step 1 : negative adsorption on CM-Sephadex. A $300 \mathrm{ml}$ portion of the supernatant liquid was applied to a column $(4.5 \mathrm{~cm} \times 38 \mathrm{~cm})$ of CM-Sephadex equilibrated with buffer A. Non-adsorbed fractions containing the enzyme activity were pooled (about $400 \mathrm{ml}$ ).

Step 2: $\left(\mathrm{NH}_{4}\right)_{2} \mathrm{SO}_{4}$ fractionation. Solid $\left(\mathrm{NH}_{4}\right)_{2} \mathrm{SO}_{4}$ to $45 \%$ saturation was added to the preparation from step 1 and the precipitate was removed by centrifugation. To the supernatant liquid further $\left(\mathrm{NH}_{4}\right)_{2} \mathrm{SO}_{4}$ was added to reach $70 \%$ saturation. The pellet was dissolved in buffer A (usually about $35 \mathrm{ml}$ ) and dialysed against the same buffer.

Step 3: chromatography on DEAE-cellulose. The preparation from step 2 was applied to a column $(4.5 \mathrm{~cm} \times 38 \mathrm{~cm})$ of DEAE-cellulose equilibrated in buffer A. A linear $\mathrm{KCl}$ gradient ( 0 to $200 \mathrm{~mm}$, total volume 2 litres) was then applied to elute xylose dehydrogenase at about $20 \mathrm{~mm}-\mathrm{KCl}$. Fractions with high enzyme activities were pooled, dialysed against buffer $\mathrm{A}$ and concentrated to approx. $5 \mathrm{ml}$.

Step 4: exclusion chromatography on Sephacryl S-300. The enzyme fraction from step 3 was layered on top of a Sephacryl S-300 column $(2.5 \mathrm{~cm} \times 75 \mathrm{~cm})$ equilibrated and eluted with buffer A containing $100 \mathrm{~mm}-\mathrm{KCl}$. Enzyme fractions were pooled, dialysed against buffer A and concentrated to about $5 \mathrm{ml}$. Only a small increase of the specific activity is accomplished at this step, but it is essential for the increase in the next step to occur.

Step 5: Chromatography on hydroxyapatite. The enzyme fraction from step 4 was adsorbed on a column $(1.3 \mathrm{~cm} \times 17.5 \mathrm{~cm})$ of hydroxyapatite mixed with an equal weight of cellulose and equilibrated with buffer $A$. Elution was accomplished with a linear gradient of $\mathrm{KH}_{2} \mathrm{PO}_{4}$ from 1 to $50 \mathrm{~mm}(\mathrm{pH} \mathrm{8)}$. Fractions with high enzyme activities were pooled, dialysed against buffer $\mathrm{A}$ and concentrated.

Step 6: chromatography on Reactive Blue 2-agarose. The preparation from step 5 was adsorbed on a column $(0.7 \mathrm{~cm} \times 12 \mathrm{~cm})$ packed with Reactive Blue 2-agarose equilibrated in buffer $\mathrm{A}$ and washed with a solution of the same buffer containing $150 \mathrm{~mm}-\mathrm{KCl}$. Xylose dehydrogenase was eluted with the same solution containing $1 \mathrm{~mm}-\mathrm{NADP}^{+}$.

\section{Protein determination}

Protein concentrations were determined by the method of Bradford (1976).

\section{PAGE}

SDS/6-20\%-PAGE was performed at $18{ }^{\circ} \mathrm{C}$ according to the procedure of Laemmli (1970). PAGE under non-denaturing conditions was performed in slab gels with the solutions described by Davis (1964).

\section{Determination of $M_{r}$}

A Sephacryl S-300 column $(75 \mathrm{~cm} \times 2.5 \mathrm{~cm})$, equilibrated with buffer A containing $100 \mathrm{~mm}-\mathrm{KCl}$, was calibrated with rabbit muscle fructose-bisphosphate 
Table 1. Purification of D-xylose dehydrogenase from pig liver

For experimental details see the text.

\begin{tabular}{lccccr}
\hline Step & $\begin{array}{c}\text { Activity } \\
\text { (units) }\end{array}$ & $\begin{array}{c}\text { Protein } \\
\text { (mg) }\end{array}$ & $\begin{array}{l}\text { Sp. activity } \\
\text { (units/mg) }\end{array}$ & $\begin{array}{c}\text { Yield } \\
(\%)\end{array}$ & $\begin{array}{c}\text { Purification } \\
\text { (fold) }\end{array}$ \\
\hline Starting supernatant & 47 & 15347 & 0.0031 & 100 & 1 \\
1. CM-Sephadex chromatography & 62 & 5416 & 0.012 & 132 & 4 \\
2. (NH4) $\mathrm{SO}_{4}$ fractionation & 70 & 2010 & 0.035 & 149 & 11 \\
3. DEAE-cellulose chromatography & 43 & 276 & 0.15 & 91 & 48 \\
4. Sephacryl S-300 chromatography & 24 & 71 & 0.34 & 51 & 110 \\
5. Hydroxyapatite chromatography & 14.6 & 9.5 & 1.54 & 31 & 497 \\
6. Reactive Blue 2-agarose chromatography & 9.9 & 1.4 & 7.1 & 21 & 2290 \\
\end{tabular}

aldolase, ovalbumin and cytochrome $c$. Void volume and internal volume were measured with Blue Dextran and $\left[{ }^{14} \mathrm{C}\right]$ lysine respectively. $M_{\mathrm{r}}$ values under denaturing conditions were estimated by SDS/PAGE calibrated with a commercial mixture of proteins of known molecular size.

\section{RESULTS}

\section{Purification of D-xylose dehydrogenase}

A typical protocol of the purification procedure (Table 1) resulted in a preparation with a specific activity of

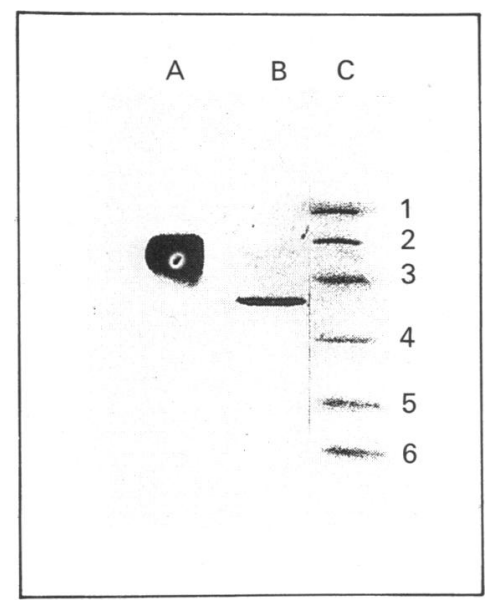

Fig. 1. PAGE of the purified D-xylose dehydrogenase from pig liver

Lane A: PAGE under native conditions. A $5 \mu \mathrm{g}$ portion of the enzyme preparation after step 6 was electrophoresed as described in the Experimental section. After the run, the gel was immersed in a reaction mixture similar to the one used for the spectrophotometric assay but containing $0.4 \mathrm{mg}$ of Nitro Blue Tetrazolium/ml and $0.04 \mathrm{mg}$ of phenazine methosulphate $/ \mathrm{ml}$. Colour development occurred in the first $2 \mathrm{~min}$. Lane B: PAGE in the presence of SDS. A $5 \mu \mathrm{g}$ portion of the same preparation was subjected to SDS/PAGE as described in the Experimental section and the gel was stained with Coomassie Blue. Lane C: a mixture of proteins of known molecular size was run in parallel with lane B $(1$, phosphorylase $b ; 2$, BSA; 3 , ovalbumin; 4 , carbonic anhydrase; 5 , trypsin inhibitor; 6 , lysozyme).
$6.1 \pm 0.7$ units $/ \mathrm{mg}$ (mean \pm S.D.; $n=6$ ) and showing only one band of protein after SDS/PAGE (Fig. 1). The enzyme was purified over 2000 -fold with a yield of about $20 \%$. The protocol can be completed in 5 days and is very reproducible. The key step is the pseudo-affinity chromatography on Reactive Blue 2-agarose.

\section{Determination of $M_{r}$}

The $M_{\mathrm{r}}$ of the native enzyme was found to be $62000 \pm 1300(n=4)$ by gel filtration (results not shown). The $M_{\mathrm{r}}$ of the denatured enzyme as determined by SDS/ PAGE (results not shown) was $32100 \pm 900(n=3)$. Thus D-xylose dehydrogenase is a dimer of subunits of equal or similar molecular mass.

\section{Effect of $\mathbf{p H}$}

Maximal rates of D-xylose dehydrogenase were found at pH 8 (results not shown).

\section{Substrate-specificity}

Several sugars or sugar derivatives (D-xylose, L-xylose, D-ribose, D-arabinose, L-arabinose, D-lyxose, D-glucose, 6-phosphogluconate, D-glucose 6-phosphate, 2-deoxy-Dglucose, D-glucosamine, D-fructose, D-fucose, L-rhamnose and D-mannose) were tested as substrates at concentrations of $100 \mathrm{~mm}$ in the presence of either $\mathrm{NADP}^{+}$or $\mathrm{NAD}^{+}$. The latter was inactive as hydrogen acceptor in all cases. Sugars found not to be substrates for xylose dehydrogenase include L-xylose (relative rate with respect to D-xylose: $7 \%$ ), D-fucose and D-lyxose $(1 \%)$. With D-mannose, D-fructose, L-rhamnose, Dglucosamine and the phosphate esters D-glucose 6-phosphate, 6-phosphogluconate and D-ribose 5phosphate relative rates were almost undetectable.

Sugars able to reduce $\mathrm{NADP}^{+}$with a relative velocity of at least $10 \%$ with respect to D-xylose were studied with greater detail (Table 2). Apparent $K_{\mathrm{m}}$ and $V_{\max }$ values were obtained according to the method of Eisenthal \& Cornish-Bowden (1974). For the calculation of $k_{\text {cat. }}$ values $\left(K_{\text {cat. }}=V_{\text {max. }} /[\mathrm{E}]_{0}\right)$, the molar enzyme concentration, $[\mathrm{E}]_{0}$, was calculated by using the $M_{\mathrm{r}}$ value of 62200 (see above). The specificity constant $K_{\mathrm{sp}}$ is expressed as the ratio $k_{\text {cat. }} / K_{\mathrm{m} \text { (app.) }}$ (Brot $\&$ Bender, 1969).

The enzyme oxidizes several pentoses and hexoses, but D-xylose showed the highest value of $K_{\text {sp. }}$. D-Ribose and L-arabinose showed $K_{\text {sp. }}$ values 6-fold and 11-fold lower respectively than that of D-xylose, and $K_{\text {sp. }}$ values with hexoses were even lower. 
Table 2. Substrate-specificity of D-xylose dehydrogenase

$V_{\text {max. }}$ and $K_{\text {m(app.) }}$ values were measured according to the method of Eisenthal \& Cornish-Bowden (1974). None of the sugars studied was able to reduce $\mathrm{NAD}^{+}$in the presence of the enzyme.

\begin{tabular}{lcllr}
\hline & $\begin{array}{c}V_{\text {max. }} \\
\text { (units/ } \\
\text { mg of } \\
\text { protein) }\end{array}$ & $\begin{array}{c}K_{\text {m(app.) }} \\
(\mathrm{M})\end{array}$ & $\begin{array}{c}k_{\text {cat. }} \\
\left(\mathbf{s}^{-1}\right)\end{array}$ & $\begin{array}{r}K_{\text {sp. }} \\
\left(\mathrm{M}^{-1} \cdot \mathbf{s}^{-1}\right)\end{array}$ \\
\hline Sugar & 7.6 & 0.0065 & 58 & 8923 \\
D-Xylose & 5.2 & 0.027 & 40 & 1481 \\
D-Ribose & 5.9 & 0.057 & 45 & 789 \\
L-Arabinose & 2.9 & 0.054 & 22 & 407 \\
2-Deoxy- & & & & \\
D-glucose & 1.1 & 0.049 & 16 & 326 \\
D-Glucose & 1.5 & 0.14 & 12 & 86 \\
D-Galactose & 1.2 & 0.13 & 9 & 69 \\
D-Arabinose & & & & \\
\hline
\end{tabular}

\section{Initial-velocity studies}

Double-reciprocal primary plots of velocity against $\mathrm{D}-$ xylose and NADP ${ }^{+}$show basically parallel lines (Figs. 2 and 3). The lines were obtained by fitting the experimental data to eqn. (1) for a ping-pong mechanism (Cleland, 1963):

$$
v=\frac{V_{\text {max }}[\mathrm{A}][\mathrm{B}]}{K_{\mathrm{m}}^{\mathrm{A}}[\mathrm{B}]+K_{\mathrm{m}}^{\mathrm{B}}[\mathrm{A}]+[\mathrm{A}][\mathrm{B}]}
$$

where $[\mathrm{A}]$ and $[\mathrm{B}]$ are the concentrations of xylose and $\mathrm{NADP}^{+}$respectively and $K_{\mathrm{m}}^{\mathrm{A}}$ and $K_{\mathrm{m}}^{\mathrm{B}}$ are the Michaelis constants for xylose and $\mathrm{NADP}^{+}$respectively.

The $K_{\mathrm{m}}$ value for $\mathrm{NADP}^{+}$of $93 \mu \mathrm{M}$ is two orders of magnitude lower than the value for xylose $(8.8 \mathrm{~mm})$. The $\mathrm{NADP}^{+}$double-reciprocal primary plots exhibit strong upward curvatures at high $\mathrm{NADP}^{+}$concentrations (Fig. $3 a$ ), indicating substrate inhibition by $\mathrm{NADP}^{+}$. The inhibition tends to disappear at saturating xylose concentrations (Fig. 3a). The value of $K_{\text {si }}$ (substrate

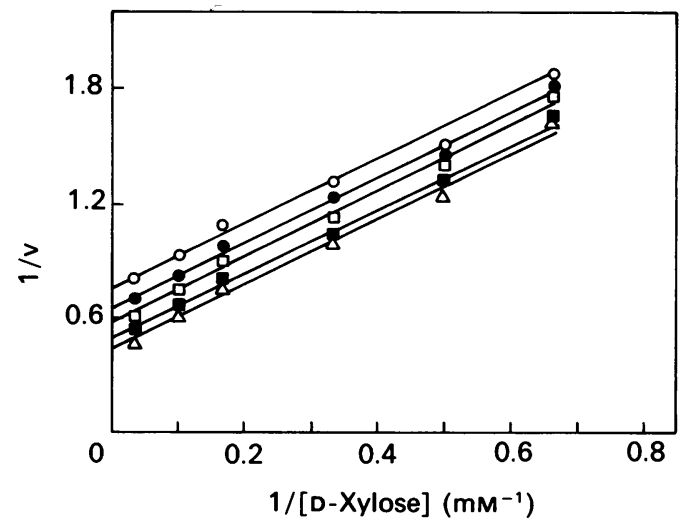

Fig. 2. Effect of D-xylose on the initial velocity of xylose dehydrogenase at various NADP $^{+}$concentrations

Assays were made at $30^{\circ} \mathrm{C}$ in a total volume of $0.5 \mathrm{ml}$ under the conditions described in the Experimental section, with $\mathrm{NADP}^{+}$and $0.04 \mathrm{~mm}(\mathrm{O}), 0.05 \mathrm{~mm}(0), 0.06 \mathrm{~mm}$ $(\square), 0.08 \mathrm{~mm}(\square)$ and $0.1 \mathrm{~mm}(\triangle)$ and xylose concentrations varied from $1.5 \mathrm{~mm}$ to $30 \mathrm{~mm}$. The lines for the reciprocal plot were drawn by using the parameters determined by fitting the data to a ping-pong reaction model by non-linear least-squares regression. The initial velocity is in $\mu \mathrm{mol}$ of NADP formed per min.

inhibition constant) for $\mathrm{NADP}^{+}$was dependent on the concentration of xylose. Thus at $50 \mathrm{~mm}-$ and $1.5 \mathrm{~mm}$ xylose the values for $K_{\mathrm{si}}$ were $48.6 \mathrm{mM}$ and $2.1 \mathrm{mM}$ respectively. Secondary plots of the intercepts and slopes of Fig. 3(b) versus the reciprocal value of xylose showed straight lines. Similar results were obtained with Larabinose as the sugar substrate (results not shown). With this pentose the $K_{\mathrm{m}}$ value for $\mathrm{NADP}^{+}$, calculated assuming a ping-pong mechanism, was $95 \mu \mathrm{M}$. If the data were fitted to a sequential mechanism the corresponding value was $70 \mu \mathrm{M}$. $K_{\mathrm{m}}$ values for L-arabinose were $88 \mathrm{mM}$ and $71 \mathrm{~mm}$ respectively. Similarly to D-xylose, inhibition by high concentrations of $\mathrm{NADP}^{+}$was observed. Detailed studies of the kind summarized above were not performed

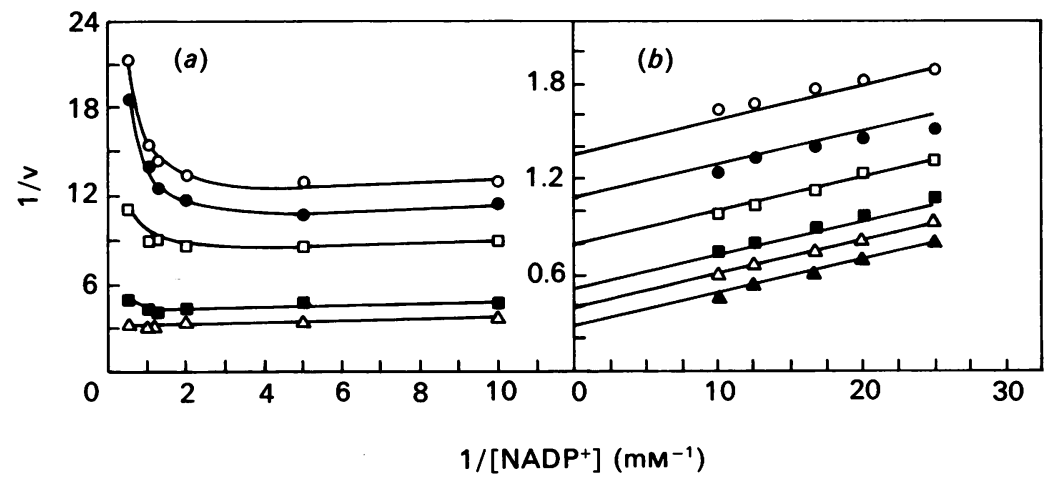

Fig. 3. Effect of $\mathrm{NADP}^{+}$on the initial velocity of xylose dehydrogenase at various $\mathrm{D}-\mathrm{xylose}$ concentrations

(a) High (0.1-2 mM) NADP+ concentrations. Xylose concentrations were $1.5 \mathrm{~mm}(\bigcirc), 2 \mathrm{~mm}(\bigcirc), 3 \mathrm{~mm}(\square), 10 \mathrm{~mm}(\square)$ and $30 \mathrm{~mm}(\triangle)$. Each line was drawn by using the calculated values for an excess-of-substrate-inhibition model by non-linear leastsquares regression. (b) Low (0.04-0.1 mM) NADP ${ }^{+}$concentrations. Xylose concentrations were $1.5 \mathrm{~mm}(\mathrm{O}), 2 \mathrm{mM}(0), 3 \mathrm{mM}$ $(\square), 6 \mathrm{~mm}(\square), 10 \mathrm{~mm}(\triangle)$ and $30 \mathrm{~mm}(\Delta)$. The lines for the reciprocal plot were drawn by using the parameters determined by fitting the data to a ping-pong reaction model by non-linear least-squares regression. Other details are as in the legend to Fig. 2. 
with other sugar substrates (i.e. those listed in Table 2), mainly because their $V_{\max }$. values were very low and apparent $K_{\mathrm{m}}$ values were not very different to that of Larabinose, which is about 10 times higher than the value for D-xylose (Table 2).

Tsopanakis \& Herries (1975) have proposed a kinetic method to discriminate between ping-pong and sequential mechanisms. In this method velocities are measured at substrate concentrations such that the second substrate concentration occurs in a number of fixed ratios to the first. Straight lines are obtained in double-reciprocal plots with ping-pong mechanisms and parabolas with sequential mechanisms. In the case of xylose dehydrogenase double-reciprocal plots of velocity versus D-xylose or L-arabinose and $\mathrm{NADP}^{+}$concentrations at a constant ratio showed straight lines (results not shown).

The data summarized so far suggest a ping-pong mechanism for the order of addition of substrates and release of products from the enzyme. However, in an ordered sequential mechanism, if $\mathrm{NADP}^{+}$were the first

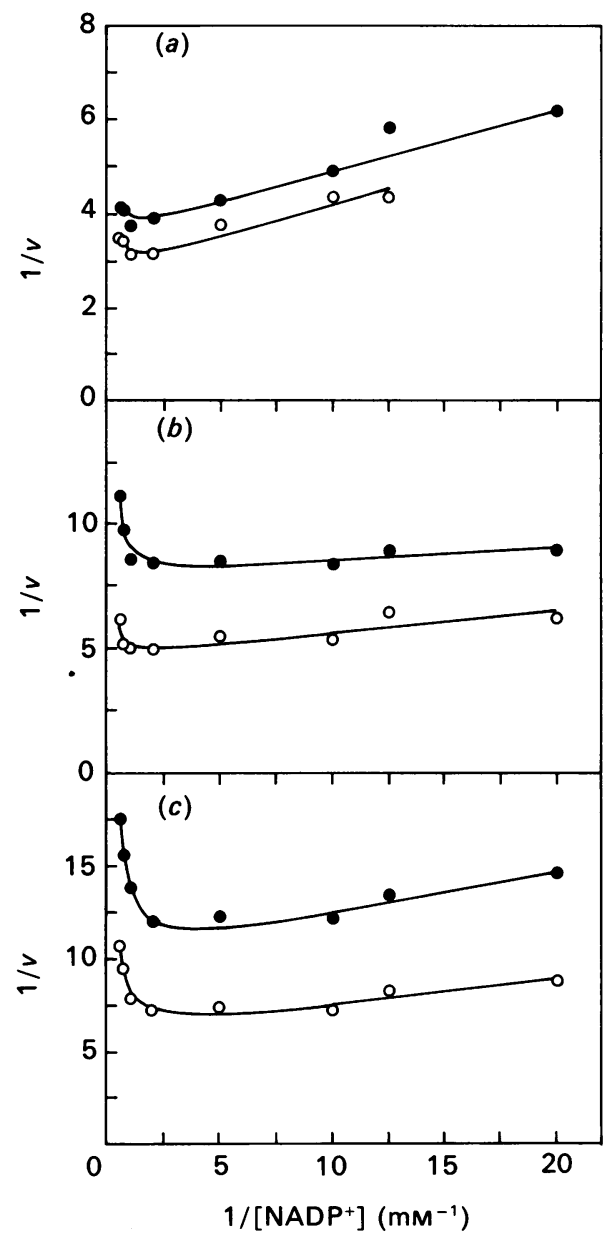

Fig. 4. Effect of D-lyxose on the initial velocity of xylose dehydrogenase at various NADP $^{+}$concentrations

Conditions were the same as for Fig. 2 with xylose at $30 \mathrm{~mm}(a), 6 \mathrm{~mm}(b)$ and $3 \mathrm{~mm}(c)$ and D-lyxose absent $(O)$ and at $100 \mathrm{~mm}(\mathrm{O})$. $\mathrm{NADP}^{+}$concentrations varied from 0.05 to $2 \mathrm{~mm}$. Each line was drawn by using the calculated values for an excess-of-substrate-inhibition model by nonlinear least-squares regression. Other details are as in the legend to Fig. 2. substrate with a lower value for $K_{\text {i }}$ than for the other kinetic constants, the equation for the initial velocity becomes similar to eqn. (1). To rule out this possibility, the experimental values were fitted to an equation for a sequential mechanism. The values obtained for $K_{\mathrm{m}}^{\mathrm{A}}$ and $K_{\mathrm{m}}^{\mathrm{B}}$ were similar to those shown above but that for $K_{\mathrm{ia}}$ was negative, and the effective sums of squares were rather similar for a ping-pong mechanism and for a sequential mechanism. With L-arabinose as substrate the $K_{\text {ia }}$ value was $9 \mu \mathrm{M}$ (with a rather large experimental error of $\pm 5 \mu \mathrm{M}$ ) and the effective sums of squares were also similar for both mechanisms. These findings suggest that the best fitting was to eqn. (1).

\section{Dead-end-inhibitor studies}

In order to resolve the ambiguity between the mechanisms proposed above, a search for dead-end inhibitors was undertaken (Fromm, 1983). D-Lyxose was found to be a linear competitive inhibitor with respect to xylose at a $\mathrm{NADP}^{+}$concentration equivalent to $2.15 \times K_{\mathrm{m}}$, with a value for the inhibition constant of $1.53 \pm 0.29 \mathrm{~mm}$ (Figure not shown). Lyxose with respect to $\mathrm{NADP}{ }^{+}$showed an uncompetitive type of inhibition at a xylose concentration equivalent to $4 \times K_{\mathrm{m}}, 0.8 \times K_{\mathrm{m}}$ and $0.4 \times K_{\mathrm{m}}$. The reciprocal plots of the data (Fig. 4) showed in all cases inhibition by NADP $^{+}$at concentrations over approx. $5 \times K_{\mathrm{m}}$.

Fig. 5 shows double-reciprocal plots for the inhibition produced by $\mathrm{NAD}^{+}$with $\mathrm{NADP}^{+}$as the substrate whose concentration was varied at xylose concentrations equivalent to $4 \times K_{\mathrm{m}}$ (Fig. $5 a$ ) and $6.6 \times K_{\mathrm{m}}$ (Fig. $5 b$ ). At both sugar concentrations the lines were essentially parallel at low $\mathrm{NADP}^{+}$concentrations. This behaviour

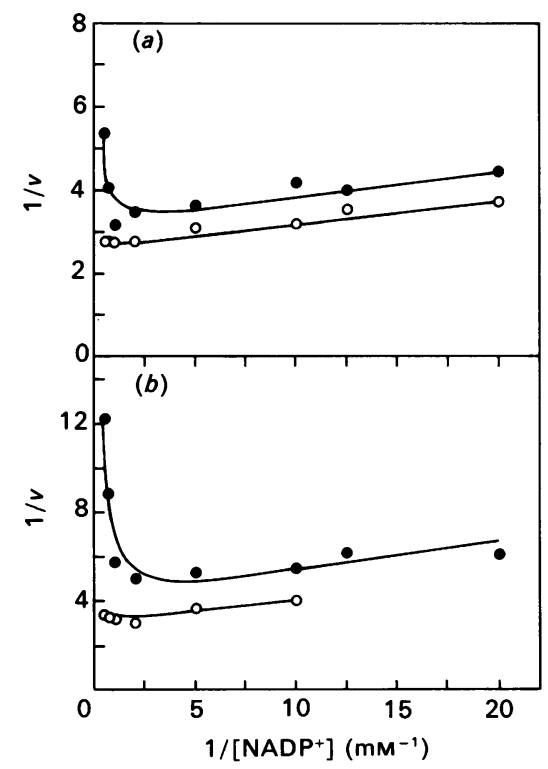

Fig. 5. Effect of $\mathrm{NAD}^{+}$on the initial velocity of xylose dehydrogenase at various NADP $^{+}$concentrations

Conditions were the same as for Fig. 2 with xylose at $50 \mathrm{~mm}(a)$ and $30 \mathrm{~mm}(b)$ and $\mathrm{NAD}^{+}$absent $(O)$ and at $5 \mathrm{~mm}(0)$. $\mathrm{NADP}^{+}$concentrations varied from 0.05 to

$2 \mathrm{~mm}$. Each line was drawn by using the calculated values for an excess-of-substrate-inhibition model by non-linear least-squares regression. Other details are as in the legend to Fig. 2. 
Table 3. $\mathrm{NAD}^{+}$-dependence of the value for the inhibition constant $\left(K_{\mathrm{si}}\right)$ by excess of $\mathrm{NADP}^{+}$in the xylose dehydrogenase reaction

$K_{\text {si(app.) }}$ and $V_{\text {max.(app.) }}$ were determined from each curve of the double-reciprocal plots shown in Fig. 5, by using the NATO Program (see the Experimental section).

\begin{tabular}{cclr}
\hline $\begin{array}{c}\text { Concn. of } \\
\text { NAD }^{+} \\
(\mathrm{mM})\end{array}$ & $\begin{array}{c}\text { Concn. of } \\
\text { xylose } \\
(\mathrm{mM})\end{array}$ & $\begin{array}{c}V_{\text {max.(app.) }} \\
(\mathrm{mol} / \mathrm{min})\end{array}$ & \multicolumn{1}{c}{$\begin{array}{c}K_{\text {silapp.) }} \\
(\mathrm{mM})\end{array}$} \\
\hline 0 & 30 & $0.33 \pm 0.013$ & $28.3 \pm 20.4$ \\
5 & 30 & $0.28 \pm 0.06$ & $1.1 \pm 0.53$ \\
0 & 50 & $0.38 \pm 0.0017$ & $48.6 \pm 7.58$ \\
5 & 50 & $0.33 \pm 0.011$ & $5.1 \pm 1.03$ \\
\hline
\end{tabular}

was confirmed with four concentrations of $\mathrm{NAD}^{+}$from 0 to $0.5 \mathrm{~mm}$ and six concentrations of $\mathrm{NADP}^{+}$from 0.04 to $0.2 \mathrm{~mm}$ (results not shown). The effect of high xylose concentrations on the inhibition produced by excess of $\mathrm{NADP}^{+}$was cancelled by NAD ${ }^{+}$(Fig. 5 and Table 3 ). With xylose as the substrate whose concentration was varied in the presence of $\mathrm{NAD}^{+}$(results not shown), the lines in a double-reciprocal plot intersected on the ordinate. The experimental data were fitted to a competitive-inhibition model and the calculated inhibition constants were $3.98 \pm 0.35$ and $4.94 \pm 0.49 \mathrm{~mm}$ at $\mathrm{NADP}^{+}$ concentrations equivalent to $2.2 \times K_{\mathrm{m}}$ and $0.9 \times K_{\mathrm{m}}$ respectively. These values are at least 40 -fold higher than the $K_{\mathrm{m}}$ value for $\mathrm{NADP}^{+}$and in the same range of $K_{\mathrm{si}}$. When the data were fitted to a mixed-inhibition model, the competitive component of the inhibition constant was in the same range of the values shown above and the inhibition constant for the uncompetitive component was two orders of magnitude higher. Therefore a mixed type of inhibition by $\mathrm{NAD}^{+}$was rejected because the residual sum of squares resulted in a higher value than that for the competitive-inhibition model. A sequential mechanism would explain the inhibition by $\mathrm{NAD}^{+}$with respect to both xylose and NADP ${ }^{+}$, since $\mathrm{NAD}^{+}$could bind to E-NADP ${ }^{+}$to form a ternary complex NAD ${ }^{+}$ $\mathrm{E}-\mathrm{NADP}^{+}$, which increases when the concentration of $\mathrm{NADP}^{+}$is increased (Fig. 5). It must be pointed out, however, that this explanation implies site-site interaction, which is not supported by the kinetics observed.

\section{DISCUSSION}

Several enzymes catalysing the nicotinamide nucleotide-linked oxidation of free pentoses have been described. The best known are those acting on Darabinose, as well as on L-fucose (6-deoxygalactose), in Pseudomonas (Palleroni \& Doudoroff, 1956; Cline \& Hu, 1965a,b,c) and Neurospora (Pincheira et al., 1973; Carrasco et al., 1981), and also in mammals (Metzger \& Wick, 1967; Schiwara et al., 1968; Schachter et al., 1969; Ureta \& Radojković, 1970; Mobley et al., 1970; Maijub et al., 1973; Carper et al., 1974; Mobley \& Metzger, 1978; Endo \& Hiyama, 1979).

D-Xylose dehydrogenases have been recognized in micro-organisms (Buchert et al., 1986, and references cited therein), but, as far as we know, only that from Arthrobacter (Yamanaka et al., 1977) has been partially purified and characterized. An NADP ${ }^{+}$-dependent xylose dehydrogenase was briefly described in pig liver (Schiwara et al., 1968; Ureta \& Radojković, 1970). A short account on a similar enzyme from pig lens has been reported (Wissler, 1977; Wissler \& Logemann, 1984). Newton et al. (1982) have published a detailed genetic study of an $\mathrm{NADP}^{+}$-dependent xylose dehydrogenase from mouse liver.

The NADP ${ }^{+}$-dependent $\mathrm{D}$-xylose dehydrogenase from pig liver is a dimeric protein of $M_{\mathrm{r}}$ about 62000 . This value is identical with the one obtained by gel filtration of a semipurified $\mathrm{NAD}^{+}$-dependent D-xylose dehydrogenase from Arthrobacter (Yamanaka et al., 1977). On the other hand, an $M_{\mathrm{r}}$ value of 48000 was reported by Wissler \& Logemann (1984) for the NADP ${ }^{+}$-dependent Dxylose dehydrogenase of pig lens.

Most sugar dehydrogenases display wide substratespecificity, a fact that should advise against undue haste in naming or assigning an EC number to a newly isolated enzyme of this type. In fact, Metzger et al. (1970) suggested that the xylose dehydrogenase activity from rat or sheep liver may be merely a marginal reaction of some other enzyme. The specificity studies discussed below suggest that the enzyme now isolated from pig liver may be considered as a xylose dehydrogenase inasmuch as D-xylose showed the highest specificity constant among 38 sugars or sugar derivatives, most of them reasonably potential substrates. The relatively high value of the $K_{\mathrm{m}}$ for D-xylose $(8.8 \mathrm{mM})$ should not be disqualifying, since $K_{\mathrm{m}}$ values in the millimolar range are not uncommon. The xylose dehydrogenase of Arthrobacter (specifically induced by D-xylose) has a $K_{\mathrm{m}}$ value for the sugar of about $17 \mathrm{~mm}$, which is even higher than that of the pig liver enzyme.
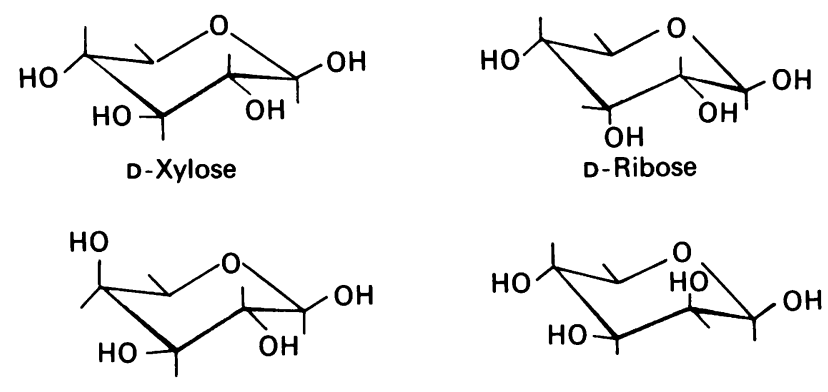

L-Arabinose

D-Lyxose<smiles>CC1(O)OC(CO)C(O)(O)C(C)(O)C1O</smiles><smiles>CC1(O)CC2(CO)CC(O)(C1)C(C)(O)O2</smiles><smiles>[2H][CH][R4](=O)(=O)O[Na]</smiles>

D-Deoxy-D-glucose<smiles>CC1(O)OC2(CO)OC1(C)C(C)(O)C2(C)O</smiles>

D-Mannose

Fig. 6. Ring structures of sugars of which some are substrates for the D-xylose dehydrogenase reaction 
Sugars listed in Table 2 were able to reduce $\mathrm{NADP}^{+}$in the presence of the dehydrogenase. The $\beta$-pyranose structures of some of the substrates and related inactive sugars are shown in Fig. 6 . The best substrate is a $\beta$-Dpentopyranose with equatorial orientation of hydroxy groups at C-2, C-3 and C-4, i.e. $\beta$-D-xylopyranose. An axial hydroxy group at C-2, as in D-lyxose or D-mannose, is incompatible with oxidation, but its absence, as in 2deoxy-D-glucose, is not. An equatorial hydroxy group at $\mathrm{C}-3$, as in D-ribose, drastically decreases 6-fold the value of $K_{\mathrm{sp}}$ mainly because of an increase in the apparent $K_{\mathrm{m}}$ value. A similar effect is apparent with respect to the hydroxy group at C-4. The primary alcohol group must be on C-5, since with hexoses the values of $K_{\mathrm{sp}}$ decrease to about $5 \%$ of the value obtained with D-xylose. Phosphorylation of the primary alcohol group, as in ribose 5-phosphate, precludes oxidation.

The same occurs with aldohexose 6-phosphates, although in the case of the pentose phosphate a predominant furanose conformation, as in D-fructose, may account for a compound's inertness as a substrate.

The parallel lines in the double-reciprocal plots of Figs. 2 and 3, the straight lines obtained in double-reciprocal plots of velocity $d$-xylose and $\mathrm{NADP}^{+}$concentrations (or L-arabinose and $\mathrm{NADP}^{+}$concentrations at a constant ratio, and the inhibition by excess of $\mathrm{NADP}^{+}$that is abolished by high xylose concentrations readily suggest a ping-pong mechanism. However, a consideration of all the results, especially the characteristics of the inhibition by $\mathrm{NAD}^{+}$and the similarity (within the experimental error) of the $K_{\mathrm{m}}$ values for $\mathrm{NADP}^{+}$with D-xylose or Larabinose as the sugar substrate, leads us to propose a sequential addition of the substrates to the enzyme in a compulsory order with $\mathrm{NADP}^{+}$as the first substrate. It is generally accepted that nicotinamide nucleotidedependent dehydrogenases follow a sequential ordered mechanism with the nucleotide as the first ligand to bind the enzyme (Dalziel, 1975), although in the case of a fish hexose-6-phosphate dehydrogenase the substrate binds before the coenzyme (Ropson \& Powers, 1988). The sugar dehydrogenase NADP $^{+}$-dependent glucose dehydrogenase and NAD ${ }^{+}$-dependent arabinose (fucose) dehydrogenase, both from pig liver, show a sequential ordered $\mathrm{Bi} \mathrm{Bi}$ mechanism (Carper et al., 1976). It is true, however, that under certain conditions some $\mathrm{NAD}^{+}-$ dependent dehydrogenases display ping-pong kinetics. That is the case for the horse and mouse liver alcohol dehydrogenases (Gershman \& Abeles, 1973) and the malate/lactate dehydrogenase (Allen \& Patil, 1972). These enzymes bind the nucleotide in such a strong way that the cofactor has even been considered as a prosthetic group rather than a substrate (Spector, 1982). In the case of pig liver D-xylose dehydrogenase further studies will be necessary to distinguish between a sequential or a ping-pong mechanism, since several enzymes have shown parallel lines in double-reciprocal plots in spite of kinetics other than ping pong, as in the case of brain hexokinase (Purich \& Fromm, 1971), a phosphofructokinase from Dictyostelium (Baumann \& Wright, 1968) and a protein kinase from Neurospora (Gold \& Segel, 1974). The recent description (Aird et al., 1987) of a prokaryotic sulphurtransferase showing parallel or converging lines in double-reciprocal plots according to the acceptor substrate employed is just another example of the difficulties that may arise in the kinetic analysis of some enzymes.
We thank members and students of the Laboratorio de Bioquímica y Biología Molecular, Facultad de Ciencias, Universidad de Chile, for encouragement and helpful discussions during the performance of this work. Thanks are due to Dr. Luz María Pérez for her helpful advice in the analysis of the specificity studies. Dr. Athel Cornish-Bowden (C.N.R.S., Marseille, France) and Dr. H. Werner Hofer (University of Konstanz, Konstanz, Germany) gave us useful comments on an earlier version of this paper. The unfailing help of Mr. Renato Besoain was indispensable for the completion of this work. Financial support from the Departamento Técnico de Investigación, Universidad de Chile (Grant B-1989) and the Organization of American States is generally acknowledged.

\section{REFERENCES}

Aird, B. A., Heinrikson, R. L. \& Westley, J. (1987) J. Biol. Chem. 262, 17327-17335

Allen, S. H. G. \& Patil, J. R. (1972) J. Biol. Chem. 242, 909-916 Baumann, P. \& Wright B. (1968) Biochemistry 7, 3653-3661

Bradford, M. M. (1976) Anal. Biochem. 72, 248-254

Brot, F. E. \& Bender, M. L. (1969) J. Am. Chem. Soc. 91, 7187-7191

Buchert, J., Viikari, L., Linko, M. \& Markkanen, P. (1986) Biotechnol. Lett. 8, 541-546

Carper, W. R., Chang, K. W., Thorpe, W. G., Carper, M. A. \& Buess, C. M. (1974) Biochim. Biophys. Acta 358, 49-56

Carper, W. R., Toews, M. L., Thompson, R. E. \& Buess, C. M. (1976) Arch. Biochem. Biophys. 175, 312-320

Carrasco, A., Pincheira, G. \& Ureta, T. (1981) J. Bacteriol. 145, 164-170

Cleland, W. W. (1963) Biochim. Biophys. Acta 67, 104-137

Cline, A. L. \& Hu, A. S. L. (1965a) J. Biol. Chem. 240, $4488-4492$

Cline, A. L. \& Hu, A. S. L. (1965b) J. Biol. Chem. 240, 4493-4497

Cline, A. L. \& Hu, A. S. L. (1965c) J. Biol. Chem. 240, $4498-4502$

Cornish-Bowden, A. (1985) Tech. Life Sci. Biochem. Suppl. B1/II (BS 115), 1-22.

Cornish-Bowden, A. \& Endrenyi, L. (1986) Biochem. J. 234, 21-29

Dalziel, K. (1975) Enzymes 3rd Ed. 11, 1-60

Davis, B. J. (1964) Ann. N.Y. Acad. Sci. 121, 404-427

Eisenthal, R. \& Cornish-Bowden, A. (1974) Biochem. J. 139, 715-720

Endo, M. \& Hiyama, N. (1979) J. Biochem. (Tokyo) 86, 1559-1565

Fromm, H. J. (1983) in Contemporary Enzyme Kinetics and Mechanisms (Purich, D. L., ed.), pp. 223-251, Academic Press, Orlando

Gershman, H. \& Abeles, R. H. (1973) Arch. Biochem. Biophys. 154, 659-674

Gold, M. \& Segel, I. H. (1974) J. Biol. Chem. 249, 2417-2423

Horecker, B. L. (1968) in Carbohydrate Metabolism and its Disorders (Dickens, F., Randle, P. J. \& Whelan, W. J., eds.), vol. 1, pp. 139-167, Academic Press, New York

Laemmli, U. K. (1970) Nature (London) 227, 680-685

Maijub, A. G., Pecht, M. A., Miller, G. R. \& Carper, W. R. (1973) Biochim. Biophys. Acta 315, 37-42

Metzger, R. P. \& Wick, A. N. (1967) Biochem. Biophys. Res. Commun. 26, 742-747

Metzger, R. P., Copp, E. F. F., Metzger, S. A. \& Wick, A. N. (1970) Metab. Clin. Exp. 19, 587-597

Mobley, P. W. \& Metzger, R. P. (1978) Arch. Biochem. Biophys. 186, 184-188 
Mobley, P. W., Metzger, R. P. \& Wick, A. N. (1970) Arch. Biochem. Biophys. 139, 83-86

Newton, M. F., Nash, H. R., Peters, J. \& Andrews, S. J. (1982) Biochem. Genet. 20, 733-745

Palleroni, N. \& Doudoroff, M. (1956) J. Biol. Chem. 223, 499-508

Pincheira, G., León, G. \& Ureta, T. (1973) FEBS Lett. 30, 111-114

Purich, D. L. \& Fromm, H. J. (1971) J. Biol. Chem. 246, 3456-3463

Ropson, I. J. \& Powers, D. A. (1988) J. Biol. Chem. 263, 11697-11703

Schachter, H., Sarney, J., McGuire, E. J. \& Roseman, S. (1969) J. Biol. Chem. 244, 4785-4792

Schiwara, H. W., Domschke, W. \& Domagk, G. F. (1968) Hoppe-Seyler's Z. Physiol. Chem. 349, 1575-1581

Segal, S. \& Foley, J. B. (1959) J. Clin. Invest. 38, 407-413

Received 11 May 1989/20 September 1989; accepted 5 October 1989
Spector, L. B. (1982) Covalent Catalysis by Enzymes, p. 33, Springer-Verlag, New York

Tsopanakis, A. D. \& Herries, D. G. (1975) Eur. J. Biochem. 53, 193-196

Ureta, T. \& Radojković, J. (1970) FEBS Lett. 9, 57-60

van Heyningen, R. (1958) Biochem. J. 69, 481-491

Weser, E. \& Laster, L. (1968) Biochem. Med. 2, 53-69

Wissler, J. H. (1977) Hoppe-Seyler's Z. Physiol. Chem. 358, $1300-1301$

Wissler, J. H. \& Logemann, E. (1984) in Methods of Enzymatic Analysis (Bergmeyer, H. U., ed.), 3rd edn., vol. 6, pp. 449-465, Verlag Chemie, Weinheim

Yamanaka, K., Gino, M. \& Kaneda, R. (1977) Agric. Biol. Chem. 41, 1501-1507

Yuen, R. \& Schachter, H. (1972) Can. J. Biochem. 50, 798-806 Zepeda, S. \& Ureta, T. (1986) Arch. Biol. Med. Exp. 19, R265 (abstr.) 